\begin{tabular}{|l|l|l|l|}
\hline Profile & N E Davidson & Serendipity and purpose & 23:5 \\
\hline
\end{tabular}

\title{
Serendipity and purpose
}

\author{
Nancy E Davidson \\ University of Pittsburgh, Cancer Institute, Pittsburgh, Pennsylvania, USA
}

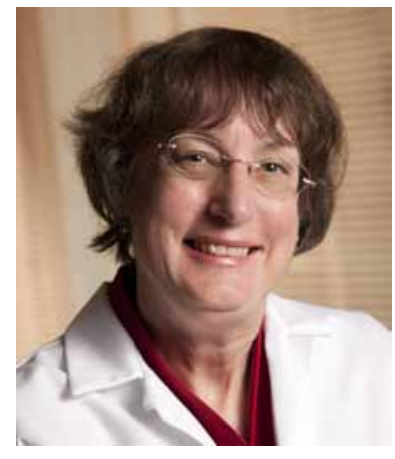

Correspondence

should be addressed

to N E Davidson

Email

davidsonne@upmc.edu

As a medical oncologist-researcher, I am often asked 'How (or why) did you go into cancer?' and 'Isn't it a depressing field?' The answer to the second question is a resounding 'no', and this brief profile charts my path to answer the first question.

Born and raised in Denver, Colorado, I am the daughter of two geologists, so ours was a scientific family. From an early age, my brother, sister and I spent many weeks each summer camping in remote areas of the western US as my father pursued field work for his job as a geologist for the US Geological Survey. Though none of us followed in our parents' footsteps, we were exposed to the excitement and beauty of earth science from an early age. A pivotal event was my father's transfer to serve as a consultant for the US Agency for International Development working with the Indian Geological Survey. Our family of five moved to New Delhi, India, when I was ninth grader, a life-altering event for all of us. For me it was the year I studied high school biology with $\mathrm{Mr}$ Warren at the American International School (New Delhi, India). After a year of international adventure, my family settled in the suburban Washington DC area where my parents served as career geologists for the US Geological Survey for several decades before their retirements.

This circuitous route led me to a weekend program on biology at the National Naval Medical Center in Bethesda, MD, USA, which cemented my interest in biomedical science, and I struck off for Wellesley College (Wellesley, PA, USA) with a tentative plan to study biology. After 2 years of course work, I decided to extend my experience into the research laboratory through the Undergraduate Research Opportunity Program at the Massachusetts Institute of Technology (MIT, Cambridge, MA, USA) to which I had access through the Wellesley-MIT partnership. Uncertain about how to proceed, I turned to the fraternity brother of the man I was dating who let me know of an opening for an undergraduate researcher in the laboratory where he worked. Armed with this connection, I showed up for an interview with Gerald Wogan whose work in aflatoxinrelated liver carcinogenesis would ultimately bring him into the National Academy of Sciences (Washington DC, USA). Despite my minimal fund of knowledge, Wogan welcomed me into the laboratory and assigned me to work with a PhD student who was just beginning his thesis on glucocorticoid effects on aflatoxin-induced liver carcinogenesis. I worked part time on that project for the next 2 years. Here I learned about the highs and the lows of science - many hours of time points in the cold room, my lack of rat surgical skills, the camaraderie of the laboratory team, and the thrill of contributing to data that led to completion and publication of a scientific story. This experience galvanized my interest in biomedical research and in cancer and led to my decision to go to medical school to maximize my career opportunities - the concept of an MD-PhD program was never brought to my attention.

Enrolling in the Harvard Medical School (Boston, MA, USA) allowed me to stay in Boston to pursue my training. Like all medical students, I was economically challenged, and after my first year, I returned to Maryland

Published by Bioscientifica Ltd. 
to live with my parents for the summer and applied for a summer research job at the National Cancer Institute (Bethesda, MD, USA). Out of nowhere came a telephone call from a postdoctoral fellow named Kent Osborne who offered me a job working with him in the laboratory of a new investigator, Marc Lippman. After verifying that this would be a paid position and accepting the job, I belatedly asked about the topic that turned out to be breast cancer research. For me this was my personal 'road to Damascus' as I found the field which would capture my interest and passion for much of my career. Marc Lippman has written about this pivotal time in his career in these very same pages (Lippman 2012), and I was fortunate to sign on during the critical time when his laboratory was caught up in establishing and characterizing human breast cancer cell lines as models for hormone-responsive breast cancer. The linkage and interplay between the laboratory and the clinic were obvious even to a novice like me, and I decided to dedicate my career to breast cancer research and practice.

Therefore, how to do that as I returned to Boston to complete 3 more years of medical school? Over those years, I discarded surgery (recall my incompetence as a rat surgeon that translated into a mediocre performance in the operating room as a medical student) and pathology (too motion sick at the microscope), and I decided to become a medical oncologist. This path was cemented by a 2-month clinical rotation at the National Cancer Institute during my fourth year of medical school and led me toward the next part of my journey, 3 years of internal medicine training to be followed by medical oncology fellowship. For personal reasons which I will outline below, I wanted very much to match with the internal medicine program at Johns Hopkins (Baltimore, MD, USA), but that was not to be. Match Day found me in tears when I was assigned to the Hospital of the University of Pennsylvania (Philadelphia, PA, USA). But off to Philadelphia, I went where I lived through the grueling but rewarding experience of medical internship and met John Glick, a medical oncologist and soon-to-be director to the University of Pennsylvania Cancer Center. Despite the welcoming and supportive environment of Pennsylvania, I was still focused on moving to Baltimore-Washington. Luckily there was an internal medicine resident at Hopkins whose life ambition was to be at Pennsylvania, and the Hopkins and Pennsylvania program directors did a swap, allowing me to complete my medical residency on the Osler Medical Service at Johns Hopkins.

Why the draw to Baltimore? Remember that I spent 2 years working as the undergraduate assistant to a PhD student at MIT who was named Thomas Kensler. As his thesis and my college career neared completion, Tom and I started dating. But I stayed in Boston for medical school and he moved to complete postdoctoral fellowships, first at the University of Wisconsin (Madison, WI, USA) and then at the National Cancer Institute. Neither of us was willing to compromise on the quality of our training, which meant that we dated long distance for 5 years. My move to Baltimore finally put us in the same state and allowed us to marry during my final year of residency. I also made the pivotal decision to return to the National Cancer Institute for my medical oncology fellowship at a time when this was one of the top training programs in the country, especially for someone who wanted to pursue a research-intensive fellowship in an epithelial cancer. Paradoxically, Tom had made the decision to take a position as a research associate at the Johns Hopkins School of Public Health around the same time.

The medical oncology fellowship at the National Cancer Institute included a most demanding first year providing total care, including overnight hospital call for cancer patients enrolled in a spectrum of clinical trials. I still remember the call schedule for our first 6 months - Carmen Allegra, Steve Averbuch, Brent Behrens, Nancy Davidson, Robert Fine, Claude Harmon, Dwight Kaufman, Richard Sorace and Stan Weiss - because of the amount and intensity of the time that we spent together learning oncology care and clinical research. Three years of laboratory-based training in breast cancer research studying markers of estrogen response in human breast cancer cells in Marc Lippman's laboratory set me up to return to Johns Hopkins as an assistant professor of oncology to establish a breast cancer program. In a fantastic stroke of luck my laboratory at Hopkins was placed into a renovated grocery store - Brown's supermarket - where I had shopped as a medical resident! It would be hard to imagine a more supportive environment as my neighbors included Bert Vogelstein, Steve Baylin and John Isaacs, all visionary scientists in cancer biology who inspired and supported our work. This was such an important lesson it is the people in your environment that make the experience, not the bricks and mortar.

Over the next $20+$ years, we built a highly productive and collegial multidisciplinary breast cancer team that was able to compete for a SPORE grant and a Department of Defense Center of Excellence at Hopkins. Our laboratory focused on the field of programmed cell death before it became fashionable, thanks to the insightful comment of my laboratory mate, John Isaacs, who was studying apoptosis in prostate cancer. In one of many discussions

Published by Bioscientifica Ltd 
as my laboratory mentor, Isaacs noted that my goal as a clinician was to kill breast cancer, and he suggested that I align my laboratory and clinic interests more closely by moving into this nascent field. Some years later a talk by laboratory neighbor, Steve Baylin, led me into the field of epigenetics and hormone response in breast cancer, an area where we still work today.

I became active at the local and national level in design and conduct of clinical trials for breast cancer and developed a career-long interest in endocrine therapy for premenopausal hormone-responsive breast cancer because of the opportunity to lead one of the key national adjuvant trials in this area, thanks to mentor, Martin Abeloff. Glick and Abeloff also paved the way for me to become involved in the American Society of Clinical Oncology as a member of committees and ultimately the board of directors. Along the way I learned that much of the excitement about the linkage between cancer biology and therapy that drew me to breast cancer was now permeating other areas of oncology. This led me to the opportunity to broaden my interests through my year as President of the American Society of Clinical Oncology. My theme was 'One Community' to reflect the need to unite all of us from every discipline to reduce the burden of cancer; my major presidential initiative was the launch of enduring activities about the cost and value of cancer care, a critical issue even today.

With this experience, I decided to take on the larger challenge of serving as Director of the University of Pittsburgh Cancer Institute, one of the nation's 45 National Cancer Institute-designated Comprehensive Cancer Centers. We are now celebrating our 30th year as the premier center for cancer research and care in western Pennsylvania, and I have the honor of working with the diverse team that makes that possible each and every day. Through my work on the external advisory boards for sister cancer centers and scientific advisory boards for cancer philanthropies, I have the chance to work across the extended family of cancer research and care. This year I will have the special opportunity to serve as President of the American Association of Cancer Research, helping all of us to have a voice about the importance of cancer research in this time of unlimited scientific opportunity and constrained resources. That we are all making a difference is reflected in the national statistics that cancer mortality is dropping by about $1 \%$ per year, not nearly enough but in the right direction.

One transcendent feature of my career has been the privilege of taking care of patients. The ability to link scientific discovery with human well-being has been an inspiration to me. I have learned from each and every patient, and each patient keeps me grounded about why we do what we do. Just last week I heard from a patient who enrolled in 1991 on the national trial of chemohormonal therapy for premenopausal women that I led - a very special type of data point indeed.

I believe this brief personal history demonstrates the role of both serendipity and purpose in defining one's path. It also reflects the extraordinary contributions of the many people with whom I have had the good fortune to work - each of us is after all a reflection and product of our community. It also ends where it began - with family. I am the daughter of two geologists, the wife of a cancer prevention researcher, the mother of a physician and a cancer epidemiologist, and the sister of a woman who lost her life to non-tobacco-related lung cancer. Like the diseases that we call cancer, my career reflects a complex interaction between genes and environment over time, but one with a most positive outcome.

\section{Declaration of interest}

The author declares that there is no conflict of interest that could be perceived as prejudicing the impartiality of this article.

\section{Funding}

This work did not receive any specific grant from any funding agency in the public, commercial or not-for-profit sector.

\section{Acknowledgements}

My work has been supported by the National Institutes of Health, American Cancer Society, Department of Defense, Susan Komen, Breast Cancer Research Foundation, and Fashion Footwear Association of New York.

\section{Reference}

Lippman M 2012 Chaos theory and a career in medicine. Endocrine-Related Cancer 19 P1-P3. (doi:10.1530/ERC-11-0341)

Received in final form 3 April 2016

Accepted 7 April 2016

Accepted Preprint published online 8 April 2016 